\title{
Future forests and indicator-species population models
}

\author{
by L.A. Venier ${ }^{1}$, J.L. Pearce ${ }^{2}$, B.A. Wintle ${ }^{3}$ and S.A. Bekessy ${ }^{4}$
}

\begin{abstract}
In this paper, we provide an overview of a project that we initiated to explore the utility of spatially-explicit metapopulation models linked to dynamic landscape models as a way of incorporating biological indicators into sustainable forest management. We developed models for three indicator species as case studies; brown creeper (Certhis americana), redbacked vole (Clethrionomys gapperi) and red-backed salamander (Plethodon cinereus) in a northern Ontario landscape. Results from the project to date suggest that there are significant advantages to models that are spatially-explicit and dynamic in their treatment of both populations and landscapes. Dynamic landscape metapopulation (DLMP) models allow a manager to track population change through time in response to a changing landscape and a fluctuating environment. These DLMP models may be used to predict the impact of current and alternative forest management strategies on population sizes of a suite of species chosen to indicate the health of forest ecosystems.
\end{abstract}

Key words: biological indicators, population viability analysis, population modeling, dynamic landscape modeling, sustainable forest management, brown creeper, red-backed salamander, red-backed vole

\section{RÉSUMÉ}

Nous procédons dans cet article à un survol d'un projet que nous avons élaboré dans le but d'explorer l'utilité des modèles de métapopulations ayant une signification spatiale certaine rattachés aux modèles dynamiques d'un écosystème en tant que moyen d'incorporer les indicateurs biologiques au sein de l'aménagement forestier durable. Nous avons élaboré des modèles pour trois espèces indicatrices de ces études de cas : le grimpereau brun (Certhis americana), le campagnol à dos roux (Clethrionomys gapperi) et la salamandre rayée (Plethodon cinereus) telles que retrouvées dans le nord de l'Ontario. Les résultats à ce jour de ce projet laissent entendre qu'il existe des avantages marqués pour les modèles ayant une signification spatiale certaine et qui sont dynamiques au niveau du traitement tant des populations que des écosystèmes. Les modèles dynamiques de métapopulations de l'écosystème (DLMP) permettent à un aménagiste de suivre les changements au sein d'une population au cours du temps suite à une modification de l'écosystème et aux fluctuations de l'environnement. Ces modèles DLMP peuvent être utilisés pour prédire l'impact des stratégies actuelles et alternatives d'aménagement forestier sur la taille des populations d'un ensemble d'espèces retenues pour être indicatrices de la santé des écosystèmes forestiers.

Mots clés : indicateurs biologiques, analyse de la viabilité des populations, modélisation des populations, aménagement forestier durable, grimpereau brun, salamandre rayée, campagnol à dos roux

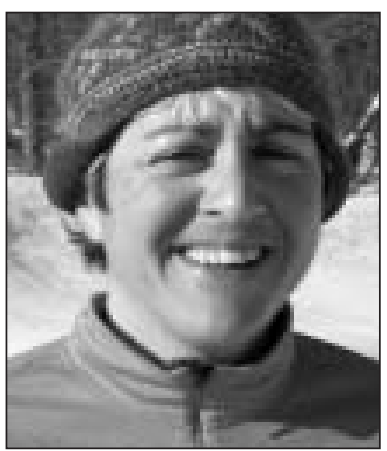

L.A. Venier

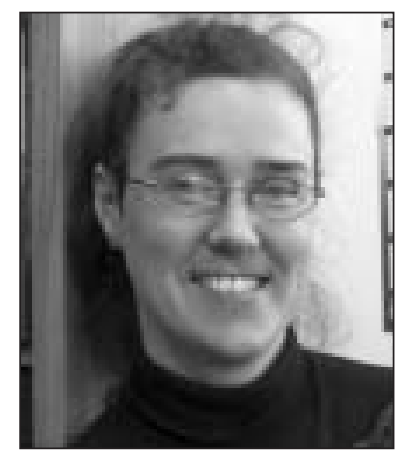

J.L. Pearce

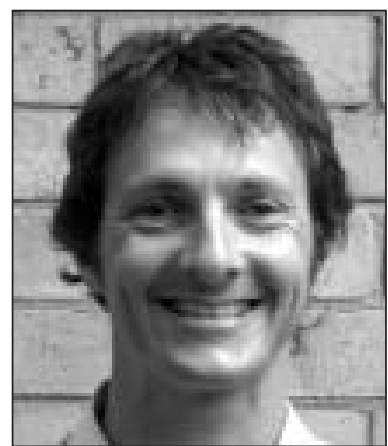

B.A. Wintle

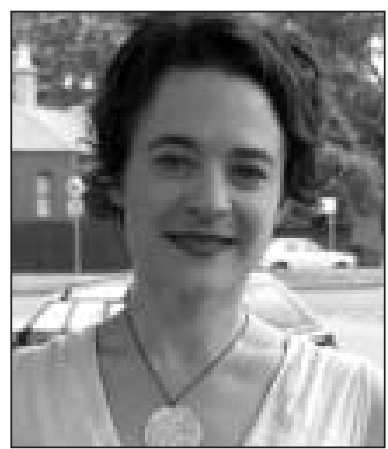

S.A. Bekessy

\footnotetext{
${ }^{1}$ Great Lakes Forestry Centre, Canadian Forest Service, 1219 Queen St. E., Sault Ste. Marie, Ontario P6A 2E5. Email: lvenier@nrcan.gc.ca ${ }^{2}$ Pearce \& Associates Ecological Research, 1405 Third Line East, Sault Ste. Marie, Ontario P6A 6J8. E-mail: jlpearce@shaw.ca

${ }^{3}$ School of Botany, The University of Melbourne, 3010 Victoria, Australia. E-mail: brendanw@unimelb.edu.au

${ }^{4}$ School of Social Science and Planning, RMIT University, GPO Box 2476V, Melbourne, 2001 Victoria, Australia. E-mail: sarah.bekessy@ ems.rmit.edu.au
} 


\section{Background}

In Venier and Pearce (2004) we argued for using spatiallyexplicit metapopulation models linked to dynamic landscape models to incorporate biological indicators into sustainable forest management. We called these models dynamic-landscape metapopulation models or DLMP models. In this paper, we provide an overview of a project that we initiated to explore the utility of these models by developing case studies for three indicator species of sustainable forest management. The objective of this paper is to inform both the forest management and scientific community of an important new approach to incorporating biological indicators into the forest management planning process. These types of dynamic and spatially explicit models are not currently used in the forest management planning process, and still need much more work to be properly developed, but before that can happen their potential needs to be explored and discussed.

Sustainable forest management requires, as one of its components, an assessment of the impact of management on biodiversity; impact is frequently assessed using individual species as indicators (McLaren et al. 1998, Mulder et al. 1999). The predicted viability of these indicator populations measures one aspect of the integrity of the system. In the past, long-term monitoring of trend in populations was considered to be an appropriate means of assessing the health of populations and therefore health of the system. More recently it has been recognized that anticipating and predicting the impact of management plans on ecological integrity is a prudent early step in their evaluation. Such predictions necessarily require the development of models of habitat or population response to management actions.

Habitat supply models attempt to address the need for predictive capability in forest management planning. For example, a habitat supply model is embedded in the SSFM (Strategic Forest Management Model) tool that is currently used in forest management planning in Ontario (Voigt et al. 2000). This tool allows users to assess how a proposed management plan for a forest management unit will change habitat supply (total habitat amount) for a selection of indicator species. This approach does not consider the arrangement of habitats across the forest management unit. It is widely recognized, however, that spatial components such as fragmentation (Haila 1999) and edge effects (Matlack and Litvaitis 1999) are important aspects of habitat quality for many species and influence habitat supply.

Another drawback of the habitat supply approach is its inability to incorporate environmental stochasticity into the evaluation of impacts. Changes in the environment through time can have large impacts on the ability of forest to provide habitat. Large-scale disturbances such as fire and logging can visibly remove habitat but environmental disturbances that, for example, decrease insect populations as food for insectivorous birds can also have more subtle impact on habitat supply. The interaction between the loss of habitat and the fluctuating environment can increase the risks to populations in ways that habitat supply models cannot anticipate.

We advocate models that are spatially-explicit and dynamic in their treatment of both populations and landscapes. Dynamic landscape metapopulation (DLMP) models allow a manager to track population change through time in response to a changing landscape and a fluctuating environment. These DLMP models may be used to predict the impact of current and alternative forest management strategies on population sizes of a suite of species chosen to indicate the health of forest ecosystems. Indicator species may be chosen to reflect a range of known and anticipated stresses on ecosystems that result from forest management.

\section{The Project}

We examined three case studies, brown creeper (Certhis americana), red-backed vole (Clethrionomys gapperi) and red-backed salamander (Plethodon cinereus). We chose these species because they are dependent on aspects of the forest system that are expected to change through forest management, they use habitat at different scales, and they have different life histories, which allowed us to explore a range of DLMP models. Brown creepers are monogamous, territorial and dependent on snags and older trees for nesting and foraging (Hejl et al. 2002). They are known to be sensitive to timber harvesting that degrades these old growth characteristics (Hobson and Schieck 1999). Red-backed salamanders are highly sensitive to micro-environmental conditions for temperature and moisture regulation (Welsh and Droege 2001). They are active over very small areas, are quite long-lived and breed biennially. Red-backed voles are dependent on old, moist forest sites with woody debris and are potentially sensitive to timber management practices that may alter understory conditions (Thompson et al. 2003). They have large population fluctuations, are polygynous and short-lived. All three species are relatively common in the study area.

The case studies were carried out in a 173 000-ha landscape in the Pukaskwa-White River region of northern Ontario. The area includes $23 \%$ of the White River management area, which has been actively managed for timber production for the past 35 years and the northeast corner of Pukaskwa National Park. As of 1970, approximately $83 \%$ of the research area was covered with mature closed-canopy forest, of which $43 \%$ was dominated by conifer forest, $33 \%$ by deciduous forest and $25 \%$ dominated by mixed forest. The main tree species in the study area are jack pine (Pinus banksiana Lamb.), black spruce (Picea mariana (Mill.) BSP), trembling aspen (Populus tremuloides Michx.), balsam fir (Abies balsamifera (L.) Mill.), and white birch (Betula papyrifera Marsh.). Harvesting in the White River management area has concentrated on mature jack pine or jack pine mixedwood stands. As of 1998 , approximately $21 \%$ of the forested portion of the research area had been harvested and replanted principally to jack pine.

Implementation of DLMP models involved five steps including (1) the development of a habitat model that describes the relationship between the occurrence of the species and mapped environmental variables (2) the development of a forest dynamics model to describe change in forest composition and age over time given natural and anthropogenic disturbances (3) the development of a dynamic population model that describes the demographics of the species (4) linking the habitat model to the forest dynamics model to describe the change in habitat through time in a spatiallyexplicit way (5) linking the population model to the spatiallyexplicit habitat maps to generate a metapopulation model. The final output of the process was a population trajectory of the indicator through time in response to the changing landscape.

We used RAMAS Landscape ${ }^{\circledR}$ (Akçakaya et al. 2003) to implement the DLMP models. RAMAS Landscape is a stand- 
alone, generic landscape and population-modeling platform composed of two separate modules: RAMAS GIS (Akçakaya and Root 2002) and LANDIS (Mladenoff and He 1999). The RAMAS GIS module simulates species' metapopulation dynamics over time. Simulations are stochastic with population parameter estimates and catastrophic events specified as a distribution of possible values with the mean and standard deviation of the distribution specified by the user. Habitat maps through time are the required input for the metapopulation model. We used literature searches, discussions with experts and local data gathered in the field on all three species (Pearce and Venier 2004, 2005; Venier and Pearce 2005) to generate habitat models and to parameterize the population models.

Habitat models were derived by examining the relationship between indicator abundance and variables measured at survey sites (e.g., tree species composition, stand height, stand age) as well as remotely derived or modeled variables (e.g., mean annual temperature, mean annual rainfall, elevation, wetness). Only environmental variables for which mapped data exist for the entire study area were considered in the habitat models because contiguous habitat maps are required for the development of DLMP models. This is a key limitation for the development of both habitat supply and DLMP models for those species that have specific habitat requirements for which no spatial information is available. The relative abundance of salamanders across the study region was mapped as a function of mean temperature of the coldest period, age of the dominant forest, wetness (a topographic variable indicating the relative moisture content of the site), the relative dominance of jack pine and elevation. Habitat for red-backed voles and brown creepers were both mapped as a function of tree species composition and stand age.

The LANDIS module simulates forest change by modeling tree species composition in ten-year age classes. It models forest succession based on interactions among species life-his- tory attributes, site conditions, disturbance regimes and management, all of which are set by the user. Life history characteristics include longevity, age at sexual maturity, shade and fire tolerance, and seed dispersal distance of tree species. LANDIS also allows the user to incorporate disturbance regimes and forest management actions. Output from LANDIS is a time series (10 year intervals) of tree species composition and age maps for the duration of the simulation. These maps are translated into a time series of habitat maps using the habitat models and then converted to a time series of patch structures for the species in question. The patch structure maps are the basis for the metapopulation model runs.

We assessed the impact of two fire regimes (natural, and fire suppression) in combination with four forest harvest regimes (no harvest, natural disturbance emulation, intensive forest management, and intensive forest management with salvage logging) for a total of eight forest management scenarios (Table 1). The pre-cut landscape (1970) was used as a starting point for our simulations and we based the management scenarios on harvesting that occurred between 1970 and 1998. More details on the scenarios can be found in Wintle et al. (2005). We ran each scenario for 1000 population model simulations on a single landscape realization. Creeper and salamander simulations ran for 160 years and the vole simulation ran for 125 years.

Sensitivity analysis was used to measure the influence of model parameters on model predictions. We used the average minimum population (MP) size as a measure of risk to the population. MP is calculated as the average of the minimum population level for each simulation run. This single value represents a good relative estimate of the risk to the population (McCarthy and Thompson 2001). We calculated the change in MP as a function of change in management scenarios or parameter estimates. Information on the exact value of several parameter estimates in each model was poor. Sensitivity analysis indicated that the parameterization of

Table 1. Details of the four forest management approaches. Two fire regimes were modeled. The first was a natural fire regime (scenarios 1, 3, 5, and 7; fire size and return time parameters set to match current estimates) and the second assumed fire suppression (scenarios 2, 4, 6, and 8; fire return times were set to 320 years for jack pine dominated forest, and 700 years for mixed forests. The fire size distribution was set to a mean of 8000 ha, an upper and lower limits of 10000 and 6000 ha respectively].
Scenarios
Harvesting Regime
1 and $2 \quad$ No timber harvesting
3 and $4 \quad$ Harvesting according to Natural Disturbance Emulation guidelines (NDE; OMNR 2001). Under these guidelines 20\% of the harvested area in the region is allowed to regenerate naturally to mixed forest, with the remainder replanted to jack pine. $10 \%$ of the stands nominated for harvesting are retained in one hectare blocks as wildlife habitat, and are not harvested. Replanted areas remain as jack pine for the length of the simulation. The total area harvested is approximately 18000 ha in each of two rotations. The first rotation starts at the beginning of the simulation. All 18000 ha are har- vested within the first 40 years of the simulation. Harvesting in the second rotation is completed between the $90^{\text {th }}$ and $130^{\text {th }}$ year of the simulation. Other prescriptions within the NDE standards and guidelines (OMNR 2001) were not modeled due to a lack of data.

5 and 6 Similar to scenario 3, but involves an increase in the intensity of silviculture. The timing of harvesting events is the same as in scenario 3. All areas nominated for harvesting are clearcut and replanted to jack pine. All replanted areas remains as jack pine for the duration of the simulation.

7 and $8 \quad$ Similar to scenario 4, though the total harvested area effectively increases, as areas burned by wild fire are then salvage logged. $20 \%$ of the salvage-logged area is allowed to regenerate naturally and the remainder is planted with jack pine. No salvage logging occurs in Pukaskwa National Park. 
Table 2. Percent decline in the minimum population (MP) size from the base scenario (\#1), and the minimum carrying capacity (K) of each scenario as a percentage of the starting carrying capacity.

\begin{tabular}{llcccccccc}
\hline Species & & $\mathbf{1}$ & $\mathbf{2}$ & $\mathbf{3}$ & $\mathbf{4}$ & $\mathbf{5}$ & $\mathbf{6}$ & $\mathbf{7}$ & $\mathbf{8}$ \\
\hline Brown creeper & \% decline in MP & 0 & 8.51 & 15.2 & 24.5 & 23.3 & 24.0 & 21.2 & 31.6 \\
& Minimum K & 99.3 & 75.5 & 89.0 & 77.6 & 90.6 & 73.6 & 76.7 & 52.0 \\
Red-backed salamander & \% decline in MP & 0 & 0.36 & 4.02 & 13.4 & 0.11 & 1.86 & 6.83 & 10.7 \\
& Minimum K & 95.9 & 97.2 & 96.8 & 69.9 & 89.4 & 93.6 & 96.3 & 79.7 \\
Red-backed vole & \% decline in MP & 0 & 28.9 & 46.2 & 51.4 & 68.6 & 55.7 & 75.3 & 63.3 \\
& Minimum K & 100 & 90.5 & 90.9 & 81.5 & 89.3 & 76.4 & 88.5 & 73.7 \\
\hline
\end{tabular}

how density dependence affected vital rates and the estimation of maximum growth rate had the greatest impact on model predictions. These parameters are very difficult to describe with certainty, even with extensive field data. As a result, it is more useful to consider a range of values for these estimates when exploring the impact of specific forest management activities on indicator species.

The impact of each scenario on the availability of habitat (in contrast to population estimates) may be expressed in terms of changes in carrying capacity in the study region over the simulation period in response to each management scenario. Carrying capacity is linearly related to the amount and quality of habitat in the region. The management scenarios increase in intensity from scenario 1 to 8 ; however, scenarios 2,4 , and 6 are all under fire suppression, which resulted in some very large fires that eliminated large areas of habitat. Estimates of minimum carrying capacity for each species (Table 1) indicate that as management options get more intense the carrying capacity tends to decrease; however, some of the largest decreases were due to large fires in scenarios two, four and six.

For most scenarios the red-backed salamander had the smallest changes in habitat availability, whereas the brown creeper had the largest. Of the three species we had the least confidence in the salamander habitat model due to the lack of empirical data for red-backed salamanders in the boreal context. However, the difficulty in defining habitat is also a problem for the development of habitat supply models. Research effort would be most efficiently used in improving our understanding of habitat use for the salamander.

The primary DLMP output is a population trajectory over the time period of the simulation. There was a lack of direct correspondence between the carrying capacity and the population trajectory, which implies that habitat supply may not be a good indicator of the current or future state of the population. The results of the population trajectory can be summarized as the expected minimum population size (MP). Correlations between the minimum carrying capacity and the minimum population size for the eight scenarios were highest for the red-backed salamander $\left(\mathrm{R}^{2}=0.665\right)$, intermediate for the red-backed vole $\left(\mathrm{R}^{2}=0.501\right)$ and lowest for the brown creeper $\left(R^{2}=0.399\right)$. This suggests that the output of the redbacked salamander model was most sensitive to habitat availability. The MP of all three species show some independence of habitat availability, which suggests that the DLMP models are adding important information to the evaluation of alternative management scenarios beyond a habitat supply model.
Under the assumptions made in these models, the current style of forest management (some combination of scenarios 4, 6 and 8) is expected to result in between $2 \%$ and $63 \%$ decrease in the expected minimum population size of the species modeled over the next 125/160 years compared to the option of no timber harvesting and no fire suppression (Table 2 ). The threat of local extinction is close to 0 . The differences between natural disturbance emulation ( 3 and 4 ) and more intensive harvesting ( 7 and 8 ) were substantial for the brown creeper and the red-backed vole but not for the red-backed salamander (Table 2). Salvage logging led to at least a $15 \%$ increase in the area harvested and had a substantial impact on all species modeled (Table 2). Fire was also an important variable for all species, with scenarios including large, infrequent fires increasing the risk of decline in many cases (scenarios 2, 4,6 , and 8 ).

\section{Conclusions and Recommendations}

These project results are preliminary but suggest that model results are sensitive to alternative management scenarios and therefore allow us to rank scenarios on the basis of impact to indicator populations. The alternative scenarios appear to result in a large range in population outcomes. As well, the fire regime appears to exert as much influence on the final population outcome as the alternative management scenarios. Much of the uncertainty in the model result came from the stochasticity in the landscape realizations. Large, infrequent fires meant that the same scenario could produce quite different landscape outcomes. RAMAS Landscape is not well designed to efficiently incorporate multiple landscape model runs and multiple population model runs into a single output. Additional code has been written (R. Chisholm and B. Wintle, personal communication) to explore and implement alternative combinations of landscape and population simulations to balance the relative contributions of landscape and population stochasticity. Research to date for the brown creeper suggests that 50 landscape simulations each with three population simulations for a total of 150 simulations is the optimal balance (Wintle et al. 2005).

Although RAMAS Landscape is well designed to explore uncertainty as it relates to demographic model parameters it does not provide an efficient means of exploring impact of habitat model assumptions or landscape model assumptions and parameter estimates such as fire frequency or fire size distribution. These uncertainties will need to be explored in future research. 
The importance of considering spatial configuration of habitat and the dynamic nature of populations has not been fully assessed in the context of forest management. There is much discussion in the scientific literature about the importance of spatially-explicit considerations in modeling. Fragmentation effects (Haila 1999), edge effects (Matlack and Litvaitis 1999) and the potential of corridors to mitigate management impacts (Lindenmayer 1994) have all been discussed as reasons why we must incorporate space into our assessments of biological indicators. DLMP models offer a means of testing the need for spatial considerations because they provide a framework for comparing models with and without space.

The reliability of the DLMP model predictions is dependent on the realism of the landscape, habitat and meta-population models. These, in turn, rely on the quality of available data and limits to understanding of ecological processes and stressors acting on bio-indicator species populations. Because we are able to consider uncertainty in our estimates of metapopulation model parameters, we are able to identify areas of the model requiring further study. The greatest advantage of DLMP models is that they allow us to explicitly describe our understanding of the system, and to incorporate environmental variability into the model, providing a distribution of predictions, rather than a single value. This is a significant advancement over existing sustainability assessment methods such as trend monitoring and habitat supply analysis. Details of the brown creeper case study can be found in Wintle et al. (2005). Results from the red-backed salamander and redbacked vole case studies are in preparation. Details are available from the authors.

Although refinements of the modelling process are needed, that does not preclude immediate use of the approach. We envision two immediate applications for DLMP models. The first is as a parallel modelling exercise to the habitat supply analysis that currently occurs as part of forest management planning. Because of the additional effort required for DLMP modelling, a small subset of potential indicator species could be identified to act as test cases for the process. Results from the two processes could be compared. The second application for DLMP models is as a tool to develop policy on the need for spatial and dynamic modelling in forest management planning. DLMP models could help to identify where and when spatial and dynamic models are necessary to get a realistic picture of the long-term risk of alternative forest management scenarios to wildlife populations.

\section{Acknowledgements}

This work was supported in part by the Ontario Living Legacy Trust, Project 07-029 and the Canadian Forest Service. R. Akçakaya, E. Bosch, M. Burgman, J. Elith, M. Flannigan, T. Lynham, M. McCarthy, and D. Mladenoff provided technical advice on the project. T. Bonnell, G. Eccles, K. Lawrence provided technical support.

\section{References}

Akçakaya, H.R., D.J. Mladenoff and H.S. He. 2003. RAMAS Landscape: integrating metapopulation viability with LANDIS forest dynamics model. User manual for version 1.0. Applied Biomathematics, Setauket, NY.
Akçakaya, H.R. and W. Root. 2002. RAMAS GIS: linking spatial data with population viability analysis (version 4.0). Applied Biomathematics, Setauket, NY.

Haila, Y. 1999. Islands and fragments. In M.L. Hunter (ed.). Maintaining Biodiversity in Forest Ecosystems. pp. 234-264. Cambridge University Press, Cambridge, U.K.

Hejl, S.J., K.R. Newlon, M.E. McFadzen, J.S. Young and C.K. Ghalambor. 2002. Brown Creeper (Certhia americana). In A. Poole and F.Gill (eds.). The Birds of North America, No. 669. The Birds of North America, Inc.,Philadelphia, PA.

Hobson, K.A. and J. Schieck. 1999. Changes in bird communities in boreal mixedwood forest: Harvest and wildfire effects over 30 years. Ecol. Appl. 9: 849-863.

Lindenmayer, D.B. 1994. Wildlife corridors and the mitigation of logging impacts on fauna in wood-production forests in south-eastern Australia: a review. Wildl. Res. 21: 323-340.

Matlack, G.R. and J.A. Litvaitis. 1999. Forest edges In M.L. Hunter (ed.). Maintaining Biodiversity in Forest Ecosystems. pp. 210-233. Cambridge University Press, Cambridge, U.K.

McCarthy, M.A. and C. Thompson. 2001. Expected minimum population size as a measure of threat. Anim. Conserv. 4: 351-355.

McLaren, M.A., I.D. Thompson and J.A. Baker. 1998. Selection of vertebrate wildlife indicators for monitoring sustainable forest management in Ontario. For. Chron. 74: 241-8.

Mladenoff, D.J. and H.S. He. 1999. Design and behaviour of LANDIS, an object-oriented model of forest landscape disturbance and succession. In D.J. Mladenoff and W.L. Baker (eds.). Advances in spatial modeling of forest landscape change: approaches and applications. Cambridge University Press, Cambridge, UK.

Mulder, B.S., B.R. Noon, T.A. Spies, M.G. Raphael, C.J. Palmer, A.R. Olsen, G.H. Reeves and H.H. Welsh. 1999. The Strategy and Design of the Effectiveness Monitoring Program for the Northwest Forest Plan. U.S. Department of Agriculture, Forest Service, Pacific Northwest Research Station. Portland, Oregon. General Tech. Rep. PNW-GTR-437.

OMNR. 2001. Forest management guide for natural disturbance pattern emulation. Version 3.1. Ont. Min. Nat. Res., Queen's Printer for Ontario, Toronto.

Pearce, J.L. and L.A. Venier. 2004. An operational methodology for measuring for measuring and analyzing bio-indicators to support sustainable forest management. Final Report to Living Legacy Trust: Project Number: 07-004.

Pearce, J.L. and L.A. Venier. 2005. Small mammals as bioindicators of sustainable boreal forest management. Forest Ecol. Manag. 208: 153-175.

Thompson, I.D., J.A. Baker and M. Ter-Mikaelian. 2003. A review of the long-term effects of post-harvest silviculture on vertebrate wildlife, and predictive models, with an emphasis on boreal forests in Ontario, Canada. Forest Ecol. Manag. 177: 441-469.

Venier, L.A. and J.L. Pearce. 2004. Birds as indicators of sustainable forest management. For. Chron. 80: 61-66.

Venier, L.A. and J.L. Pearce. 2005. Boreal bird community response to jack pine forest succession. Forest Ecol. and Manag. 217: 19-36.

Voigt, D.R., J.A. Baker, R.S. Rempel and I.D. Thompson. 2000. Forest vertebrate responses to landscape-level changes in Ontario. In A.H. Perera, D.L. Euler and I.D. Thompson (eds.). Ecology of a Managed Terrestrial Landscape: Patterns and Processes in Forest Landscapes of Ontario. pp. 198-233. UBC Press, Vancouver, BC.

Welsh, H.H. and S. Droege. 2001. A case for using plethodontid salamanders (Family Plethodontidae) for monitoring biodiversity and ecosystem integrity on North American forestlands. Conserv. Biol. 15: 558-569.

Wintle, B.A., S.A. Bekessy, L.A. Venier and J.L. Pearce, R.A. Chisholm. 2005. Utility of dynamic-landscape metapopulation models for sustainable forest management. Conserv. Biol. 19: 1930-1943. 